\title{
Impact of demographic variables on emotional intelligence levels amongst a sample of early career academics at a South African higher education institution
}

\begin{tabular}{|c|c|}
\hline \multicolumn{2}{|c|}{$\begin{array}{l}\text { Authors: } \\
\text { Matthew Marembo }{ }^{1} \\
\text { Willie T. Chinyamurindi }\end{array}$} \\
\hline \multicolumn{2}{|c|}{$\begin{array}{l}\text { Affiliations: } \\
{ }^{1} \text { Department of Industrial } \\
\text { Psychology, University of } \\
\text { Fort Hare, South Africa }\end{array}$} \\
\hline \multicolumn{2}{|c|}{$\begin{array}{l}{ }^{2} \text { Department of Business } \\
\text { Management, University } \\
\text { of Fort Hare, South Africa }\end{array}$} \\
\hline \multicolumn{2}{|c|}{$\begin{array}{l}\text { Corresponding author: } \\
\text { Willie Chinyamurindi, } \\
\text { chinyaz@gmail.com }\end{array}$} \\
\hline \multicolumn{2}{|c|}{$\begin{array}{l}\text { Dates: } \\
\text { Received: } 01 \text { Mar. } 2018 \\
\text { Accepted: } 23 \text { Aug. } 2018 \\
\text { Published: } 07 \text { Nov. } 2018\end{array}$} \\
\hline \multicolumn{2}{|c|}{$\begin{array}{l}\text { How to cite this article: } \\
\text { Marembo, M., \& } \\
\text { Chinyamurindi, W.T. (2018). } \\
\text { Impact of demographic } \\
\text { variables on emotional } \\
\text { intelligence levels amongst a } \\
\text { sample of early career } \\
\text { academics at a South African } \\
\text { higher education institution. } \\
\text { SA Journal of Human Resource } \\
\text { Management/SA Tydskrif vir } \\
\text { Menslikehulpbronbestuur, } \\
\text { 16(0), a1051. https://doi.org/ } \\
\text { 10.4102/sajhrm.v16i0.1051 }\end{array}$} \\
\hline \multicolumn{2}{|c|}{$\begin{array}{l}\text { Copyright: } \\
\text { (c) 2018. The Authors. } \\
\text { Licensee: AOSIS. This wo } \\
\text { is licensed under the } \\
\text { Creative Commons } \\
\text { Attribution License. }\end{array}$} \\
\hline \multicolumn{2}{|l|}{ Read onlin } \\
\hline 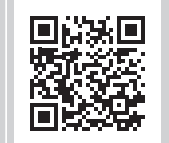 & $\begin{array}{l}\text { Scan this QR } \\
\text { code with your } \\
\text { smart phone or } \\
\text { mobile device } \\
\text { to read online. }\end{array}$ \\
\hline
\end{tabular}

Orientation: Emotional intelligence (EI) is highlighted by the literature as an important attribute that enables an individual to cope with changes and pressures in the work environment and subsequently yields consistent performance. However, some scholars debate the role of demographic diversities and their impact on levels of EI amongst individuals.

Research purpose: This study examined the influence of demographic variables on EI levels amongst early career academics (ECAs).

Motivation for the study: The study interrogates demographic variables and EI, two issues important in the 21st-century workforce setting. The relationship between the two may be of value to the debate surrounding the success of early career professionals in the higher education sector. The success of ECAs should be of importance to institutions of higher learning.

Research approach/design and method: A quantitative approach was followed in conducting the study. Data were collected from a sample of 220 ECAs in a selected university in South Africa. A self-administered questionnaire was sent to the participants using SurveyMonkey online data collection tool. EI was measured using the Schutte Emotional Intelligence Scale.

Main findings: Significant EI level differences were observed based on the participants' ethnic background. However, no significant differences in EI levels could be found based on the respondents' gender, age and work experience.

Practical/managerial implications: The findings may be relevant to career management and human resources forecasting.

Contribution/value-add: The study adds to the literature on EI and career success of early career professionals.

\section{Introduction}

Emotional intelligence (EI) is increasingly gaining empirical attention as a predictor of individual productivity and performance (Bande, Fernández-Ferrín, Varela, \& Jaramillo, 2015). Despite the criticism in terms of instruments of measurement (Antonakis \& Dietz, 2011; Murphy, 2014), many authors agree that EI impacts individual performance (e.g. Bissessar, 2011; Moon \& Hur, 2011; Steyn, 2010; Vratskikh, Masadeh, Al-Lozi, \& Maqableh, 2016). According to Pradhan, Jena and Sing (2017), EI is positively related with self-efficacy, which is an important attribute of psychological capital. This makes the subject of EI important because organisations continue to search for ways that may enable their human capital to perform consistently. In this regard, keeping EI levels high is especially important as it is highly associated with an individual's ability to cope with diversity and change (Bande et al., 2015; Kaufmann \& Wagner, 2017).

Every profession has its challenges that may cause psychological stress and upset the professionals' emotional balance (Oatley \& Johnson-Laird, 2014). However, this study asserts that early career academics (ECAs) may be facing a higher degree of emotional imbalance. This is because of an argument that the ECAs are entering into academia at a time that the profession is experiencing dramatic changes that are complicating the requirements and standards of entry (Coates, Goedegebuure, \& Meek, 2015). Furthermore, the academic profession has grown more competitive as instigated by increased human capital mobility across national and continental 
borders (Coates et al., 2015). In view of this, the global economy has grown to be knowledge-driven, making research an integral part of the academic field (Andrés, Asongu, \& Amavilah, 2015).

The per-annum enrolment in institutions of higher learning has been on the rise for the past two decades (Coates et al., 2015). Early career academics are usually contracted to facilitate and assess the junior classes, which consist of more students than senior or higher level classes (Brock, 2010). Furthermore, the professional work of the academics requires interpersonal connectedness. All these circumstances may instigate negative emotions, and when not managed properly, individual efficiency and effectiveness may be hampered. Given this, EI comes into play based on the assertions that it can enhance communication effectiveness (Jorfi, Yaccob, \& Shah, 2011; Smith, Ciarrochi, \& Heaven, 2008), academic achievement (Kumar \& Muniandy, 2012), work and organisational psychology (Bissessar, 2011; Moon \& Hur, 2011; Vratskikh et al., 2016) and individual psychological wellness (Steyn, 2010). Therefore, it follows that an individual's level of EI becomes important as it may determine the level of one's performance in different aspects.

However, the individual's level of EI may be influenced by several factors. According to Pooja and Kumar (2016), EI levels can be explained by biological, psychological and social factors. Some scholars promote the idea that EI is improvable probably through some enhancement programmes and awareness workshops (Ebrahimi, Khoshsima, \& Zare Behtash, 2018). Taking from the assertions made by Hemalatha (2014) and Kónya, Matić and Pavlović (2016), this study focused on the demographic variables (age, gender, work experience and ethnic background) as predictors of the level of EI.

\section{Research purpose and objectives}

The demographic make-up of the workforce may be the basis for differences in terms of perceptions, values and attitudes amongst employees (Pooja \& Kumar, 2016). At a time of globalisation, the gender, age and ethnic distribution are increasingly changing because of cross-national and crosscontinent mobility of labour (James \& Steger, 2014). The academic profession in South Africa has experienced some changes as a result of foreign academics' mobility and also policy provisions that seek to redress the inequalities (Coates et al., 2015). Thus, the changes to the demographic profile of the academic workforce are increasingly shifting more than before. Despite these changes, the academics are expected to perform at the best of their ability. Emotional intelligence as a predictor of individual performance may be affected by the changing demographic variables because more differences in values, priorities and culture are presented (Shukla \& Srivastava, 2016). In addition, many scholars continue to call for the interrogation of EI as far as performance is involved because criticism still exists on the measurement of both EI and performance (Antonakis, Ashkanasy, \& Dasborough, 2009; Fiori \& Antonakis, 2011). As that may be, the literature focuses on proving the role of EI on performance (Bailey, 2015). Little research exists on matters influencing the level of EI, and the studies that focused on enhancing EI did not do so in the context of ECAs. The primary objective of this study was to investigate how some demographic variables influence the EI levels amongst ECAs in a selected university in South Africa. Furthermore, the study sought to identify the existent demographic variables and establish their relationship with EI amongst ECAs.

The article provides a literature review on EI, demographical variables and the relationship between the two. This is followed by an overview of the research design utilised to carry out the study. Findings of the study are also presented as well as recommendations for ECAs, management of institutions of higher learning and proposals for future research.

\section{Literature review}

\section{Emotional intelligence}

Kumar and Muniandy (2012) defined EI as the rightful or sound use of the discovered emotions in making decisions and taking behavioural actions. Similarly, according to Serrat (2017), EI is a process or state of being that enables one to accomplish expected end goals by managing one's behaviour and the behaviour of those near. EI involves being sensitive to emotions of self and others. The term EI first appeared in 1964 from the work by Beldoch and this was proceeded by Leuner in 1966 (Serrat, 2017). Major developments on the concept of EI appeared in the work by Gardner (1983) who highlighted the existence of multiple intelligences in explaining one's cognitive ability. The term gained popularity outside the academic circles through the writings of Goleman (1995) who described EI as an array of skills and attributes that influence leadership performance. This, however, sparked a scientific debate which provided the groundwork for the divide between ability and trait conceptions of EI. The ability model developed by Salovey and Mayer (1990) defines EI as an ability to robustly reason with emotions to enlighten the thought process. Common under the ability conception are the four ability dimensions, namely recognition of emotions, understanding emotions, managing emotions and utilising emotions (Mayer, Caruso, \& Salovey, 2016).

This study utilises the trait model of EI which according to Petrides, Pita and Kokkinaki (2007) is a set of emotional self-perceptions usually found at the lower levels of personality hierarchies. Petrides (2011) argues that trait EI cannot be classified under the conception of the human cognitive ability. Trait EI exhibits an individual to be the only one with direct access to information that shapes his or her judgements of various emotional phenomena (Bozionelos \& Singh, 2017). In this regard, trait EI is the only operational definition that acknowledges the inherent subjectivity of the emotional context (Petrides, 2011). Trait $\mathrm{EI}$ is a collection of self-perceptions and in this light many self-report instruments have been developed to measure trait EI and these include Swinburne University Emotional 
Intelligence Test, Trait Emotional Intelligence Questionnaire, EQ-I 2.0 and the Schutte Emotional Intelligence Scale (SEIS). The researchers adopted the SEIS developed by Schutte et al. (1998) which has been used extensively in the literature and can be employed as a short measure of global trait EI (Petrides, 2011). Though the SEIS was developed off the EI model by Salovey and Mayer (1990), it is closely associated with the EQ-I model of EI and it is a limited measure of trait EI (Petrides et al., 2007)

Bar-On (2010) made an empirical inquiry in which EI was found to be highly associated with positive psychology, which includes individual performance, happiness, wellbeing and an individual's meaning of life. Botma (2009) reports similar findings citing that EI is very instrumental in avoiding and coping with stressful situations and burnout. Thus, emotional skills to manage stressors become important in ultimately enhancing or maintaining an individual's psychological and physiological well-being. The studies reviewed also show that in South Africa, scholars are starting to apply the construct EI to different contexts. Dippenaar and Schaap (2017) took the context of coaching EI and social intelligence amongst leaders in a financial services sector. Ramesar, Koortzen and Oosthuizen (2009) related EI to stress management context. There is also growing interest in the applicability of EI to the higher education context given that it is linked to enhanced personal and group performance (Black, 2015). According to Vandervoort (2006), there are potentially many personal, interpersonal and societal benefits in incorporating EI in higher education. Since Zysberg, Orenshtein, Gimmon and Robinson (2017) found EI to be important in reducing burnout amongst school educators, the same can be expected for academic professionals at a higher education level. Chengting, Jijun, Yuan, Wei and Xuqun (2015) also report that EI and workplace social support protect educators from burnout. This is justified by the finding that the teaching process stirs inner emotions emanating from dealing with heavy workloads of class facilitation assessment and research activities (Armour, 2012). Research is becoming an important part of the performance benchmarks in higher education leadership and teaching and as such EI can be viewed as a significant contributor taking from the submission by Collins and Cooper (2014) in their conceptual article which concluded that EI is useful in advancing qualitative research and building up novice researchers. However, in the South African context, little research is available in modelling EI in the higher education context. Mayer, Oosthuizen and Surtee (2017) conducted a qualitative study on 23 South African women leaders in higher education institutions. Results revealed that these women leaders referred more to the intrapersonal aspect of EI, followed by the interpersonal and then emotional management. The importance of the study by Mayer et al. (2017) is that it examined and explored original contextspecific insights on EI in higher education in South Africa and it informs on EI training. This study therefore has significance on what is known about EI and its application in higher education in South Africa.

\section{Emotional intelligence and demographic variables}

Studies exist that examined whether levels of EI vary across different demographic variables of individuals (e.g. Jorfi et al., 2011; Kumar \& Muniandy, 2012; Pooja \& Kumar, 2016; Sergio, Dungca, \& Ormita, 2015; Shukla \& Srivastava, 2016). The common demographic variables studied include but are not limited to age, gender, educational qualifications, work experience, job position and marital status (Sergio et al., 2015). The interest in studying these demographic variables against EI has spiralled because human resources managers and other concerned organisational authorities are of late experiencing demographic diversity at a higher level both internal and external to their organisations (Shukla \& Srivastava, 2016). Notably, no study has investigated EI and demographic variables amongst ECAs.

\section{Gender}

According to Jorfi et al. (2011) gender constitutes a complex set of interwoven cultural values that consciously or unconsciously influence an individual's perception of himself or herself as a woman or man, an individual's typical expectations on women and men and the kind of results an individual anticipates to achieve. Literature exists that postulates gender as a predictor of people's aspirations, perspectives, behaviours and attitudes (Jorfi et al., 2011; Pooja \& Kumar, 2016; Shukla \& Srivastava, 2016). Mixed conclusions on gender differences and EI are observed in prior studies. Sergio et al. (2015) found some significant differences in EI levels based on the gender of call centre representatives. This is supported by Jorfi et al. (2011) who emphasise that women are more socially skilful than men, and hence differences in EI are present.

In a study on retail employees by Shukla and Srivastava (2016), an independent Pearson correlation was conducted and found significant differences in the scores of EI based on respondents' gender with female respondents scoring higher than their male counterparts. Female employees in the Indian service sector also scored higher in EI than the male employees (Pooja \& Kumar, 2016). The reason for women scoring higher on EI may be ascribed to their traditional primary roles of caregiving to children which give them awareness and responsiveness to human non-verbal expressions and emotions (Frank, Baron-Cohen, \& Ganzel, 2015). Even though many studies found significant differences based on gender, other studies could not find these differences (Gunkel, Schlägel, \& Engle, 2013; Kumar \& Muniandy, 2012). This is because gender roles are converging and thereby placing both men and women in similar circumstances which may see them adapt more or less the same. This is to say that the influence of gender on the level of EI in individuals is still under study and as research continues to be carried out on the subject of EI, a trend on gender influence may become visible in future (Kumar \& Muniandy, 2012). In addition, as men are increasingly becoming caregivers to their children and other dependents, a neurological adaptation to social skilfulness may be observed in years to come and the gender influence may become complex (Gunkel et al., 2013). 


\section{Age}

Age is believed to be associated with the level of social adaptability and awareness (Frank et al., 2015). Older members of the society are assumed to have gone through many more circumstances than the younger counterparts and hence would have developed better flexibility and adaptability in their social interactions and in dealing with their own emotions (Sergio et al., 2015). Findings on polytechnic lecturers by Kumar and Muniandy (2012) reveal that EI rises with age up to 50 years and tends to decline as the subjects grow beyond 50 years. This positive relationship between age and EI is supported by Jorfi et al. (2011), in the literature review on educational administrations in Iran. A study by Chen, Peng and Kirk (2015) on Chinese and American adults concluded that age was positively related to emotional appraisal and regulation in self and negatively related to appraisal and use of emotion in others. College students in Bermuda and Trinidad had their age significantly related to their EI levels (Bissessar, 2011). Even though the reported positive correlation between age and EI is contested, it is clear that the research on the matter is ongoing and changes to the existing trends might or might not materialise.

\section{Work experience}

The time that an individual spends in a certain field of profession is important for the individual to become exposed, acquainted and versed in the dynamics of the profession (Shukla \& Srivastava, 2016). The longer the time spent in the profession, the greater the experience, adaptability and knowledge that is gained by the individual. In this regard, it is deemed logical that individuals with more work experience possess higher levels of EI than those who are novices to the respective profession. According to Jorfi et al. (2011), employee work experience is positively related to EI meaning that EI increases with the number of years one has served in a profession. This finding is supported by Kumar and Muniandy (2012) who found EI to significantly vary with lecturers' teaching experience. In a study on retail employees by Shukla and Srivastava (2016), the findings corroborated work experience differences in trait EI. Emotional intelligence value increases with an increase in the number of years of work experience and reaches its peak when the employee has worked for around 16-20 years, with a further increase in the years of work experience causing the EI value to fall for the employees (Pooja \& Kumar, 2016). However, Sergio et al. (2015) argue that work tenure, which translates to work experience, has no significant relationship with the EI amongst call centre employees in the Middle East, Iran, Pakistan, Russia, India and the Philippines. Even though mixed findings on the influence of work experience on EI exist, work experience can be considered an important aspect in today's work environment that needs good social skills and sound self-management towards the achievement of goals (Sergio et al., 2015; Shukla \& Srivastava, 2016).

\section{Ethnicity and nationality}

Ethnicity background and/or nationality has been found in social studies to corroborate differences in beliefs, values and disturbance handling processes (Maduramente, 2015). At a time of globalisation and growing diversity, understanding how nationality and ethnicity backgrounds affect employees' well-being, decision making and productivity is important. In one cross-cultural study, EI differences were observed in terms of the respondents' nationality (Ang, Rockstuhl, \& Tan, 2015; Sergio et al., 2015). This result is supported by Dewi, Halim and Derksen (2017), who found that EI competencies varied significantly across three ethnic groups in Indonesia.

However, Hossein (2015) in his doctoral thesis on leaders carried out a quantitative analysis of the relationship between EI and nationality. The result showed no significant differences in the trait EI and the nationality of the interviewed leaders. Robertson (2010) also found no significant relationship between EI and the ethnicity of respondents in an urban school. The reason may be that those from different ethnic groups employed in the school could have been endowed with rich adaptability competencies to work in diverse cultures hence. Based on this, it can be expected that:

$\mathbf{H}_{1}$ : There are significant differences in the ECAs' EI levels on the basis of their gender, age, working experience and ethnicity.

\section{Research design Research approach}

The study followed the quantitative nature in which data were collected from numerous respondents by means of a self-administered questionnaire and statistical tests were carried out to meet the main objective of the study, which was to examine the influence of demographical variables on the level of EI amongst ECAs.

\section{Research participants}

The population of interest in this study was the ECAs at a rural South African campus in the Eastern Cape Province. The ECAs being referred to in this study were defined according to the following criteria:

- All doctoral candidates helping with research supervision and facilitation of classes.

- All postdoctoral fellows.

- Research assistants, time-on-task lecturers.

- Lecturers or researchers still within 8 years of their first academic appointment or research practice.

Using the criteria determined above, the population amounted to 401 participants. In collecting data, the researchers send the research instrument to those that were readily available and willing to take part in the study and a total of 220 responses were qualified for data analysis. This was satisfactory for the study because the number surpassed the predetermined Raosoft sample size of 158 at 5\% margin of error and 50\% expected response rate.

\section{Measuring instruments}

The study employed a self-administered questionnaire that had two sections. The first section had questions on the 
demographic aspects of respondents that included gender, age, faculty, position held, work experience and ethnical background. The second section consisted of the SEIS (Schutte et al., 1998) which was used to measure EI. A final 33-item scale was developed by Schutte et al. (1998) from an initial 62 items. The SEIS is composed of 33 Likert scale items ranging from 1 (strongly disagree) to 5 (strongly agree). There are three reverse-scored items on the SEIS which are item 5 ('I find it hard to understand the non-verbal messages of other people'), 28 ('when I am faced with a challenge, I give up because I believe I will fail') and 33 ('it is difficult for me to understand why people feel the way they do'). A principalcomponents, orthogonal rotation reduced the 62 items to four factors in which 33 items loaded to one factor which represented all the dimensions of EI from the Salovey and Mayer (1990). Schutte et al. (1998) obtained a reliability value of 0.90 for the whole scale.

In this study, the Cronbach's alpha for the 33 items on the SEIS is 0.797 (see Table 1) and this value is between 0.7 and 0.8 . This means that the items on the scale have an acceptable internal consistency in measuring the construct EI. The obtained Cronbach's alpha is within the range reported by Jonker and Vosloo (2008) of between 0.7 and 0.8. However, it is marginally lower than the 0.9 obtained by Thomas, Cassady and Heller (2017). This prior research is evidence that the SEIS is a consistent measure of EI.

\section{Research procedure and ethical considerations}

In collecting the data, the researchers physically distributed the questionnaires and also utilised the online SurveyMonkey, whereby targeted respondents followed a link that was sent through to their personal emails. Follow-ups were made both in person and through the personal email. Respondents' identity was kept confidential and so were the responses that were given which were treated with care to ensure anonymity and to prevent any damage to the person or the respondent. The researchers also ensured that the participants signed the consent form as evidence of their agreement to participate in the study.

\section{Statistical analysis}

The data collected were entered into the Statistical Package for Social Sciences version 22 software for analysis. Frequency distribution tables were utilised to summarise the demographic features of the data from the sample and measures. Analysis of variance (ANOVA), chi-square test and ordinal (proportional odds) regression analysis was conducted to test the hypotheses to the study.

\section{Ethical consideration}

The proposal and questionnaire of the study were reviewed by a research ethics committee and an ethical clearance certificate

TABLE 1: Cronbach's reliability test.

\begin{tabular}{lcl}
\hline Cronbach's alpha & Number of items & Example item \\
\hline 0.797 & 33 & $\begin{array}{l}\text { I present myself in a way that makes } \\
\text { good impression on others }\end{array}$ \\
\hline
\end{tabular}

(REC-270710-028-RA level 1) was granted. Ethical clearance reference number: CHI191SMAR01.

\section{Results \\ Demographic frequency distribution}

The findings indicated that there were $95(43.2 \%)$ men and $125(56.8 \%)$ women. In terms of the participants' age, 30.9\% $(n=68)$ indicated to be aged between 20 and 30 years, $46.8 \%$ $(n=103)$ were aged between 31 and 40 years, 19.1\% $(n=42)$ were aged between 41 and 50 and only 7 (3.2\%) were older than 50 years. Of the 220 participants, 2 did not indicate the positions they hold in their respective departments. Of the respondents, 76 (34.9\%) were full-time lecturers, 19 (8.7\%) were senior lecturers, 41 (18.8\%) were postdoctoral fellows, $48(22 \%)$ were doctoral candidates and lastly 34 (15.6\%) were research assistants or time-on-task staff. Despite the fact that all the participants were categorised as ECAs, their level of experience was not the same. Of the respondents, $28.7 \%$ $(n=62)$ were still within two years of experience, $33.3 \%$ $(n=72)$ had 3-4 years of experience and 38\% $(n=82)$ had between 5 and 8 years of experience. Another important profile for the participants was their ethnic group. One hundred and ninety-six respondents were black Africans, 17 were white and four were mixed race. Three indicated 'other' but did not state their race.

Based on Table 2, 22 out of the 33 items on the SEIS do have means that are above their median value. In addition, the modal scores for 30 out of the 33 items were 4 or 5 . This is evidence that the ECAs surveyed generally showed their agreement with the EI attributes as far as the items on the SEIS can tell. These findings suggest that ECAs do possess high levels of EI.

\section{Hypothesis testing}

The proportional odds ordinal regression analysis was conducted on the data to test the hypothesis that the demographical variables (gender, age, working experience and nationality and ethnicity) significantly influence levels of EI amongst ECAs. Ordinal regression works well under the assumptions that there is non-multicollinearity amongst the independent variables and that each independent variable has an identical effect at each cumulative split of the ordinaldependent variable. The multicollinearity diagnosis showed all the variance inflator factor values to be less than the threshold of three showing that there were no significant issues of multicollinearity amongst the independent variables. This meant that ordinal regression was applicable to the data.

In conducting the ordinal regression analysis, it was important to test whether the study model is better than the null model, which is without factors or covariates. A $p$-value of 0.031 (Table 3 ) was obtained meaning that the study model is basically better than the null model.

Following the goodness of fit test is important. The assumed null hypothesis here is that the study model is adequately 
TABLE 2: Descriptive statistics on the Schutte Emotional Intelligence Scale.

\begin{tabular}{|c|c|c|c|c|c|c|}
\hline \multirow{2}{*}{$\begin{array}{l}\text { Emotional } \\
\text { Intelligence }\end{array}$} & \multicolumn{2}{|c|}{$N$} & \multirow[t]{2}{*}{ Mean } & \multirow[t]{2}{*}{ Median } & \multirow[t]{2}{*}{ Mode } & \multirow{2}{*}{$\begin{array}{c}\text { Std. } \\
\text { deviation }\end{array}$} \\
\hline & Valid & Missing & & & & \\
\hline El1 & 216 & 4 & 4.37 & 4.00 & 4 & 0.529 \\
\hline $\mathrm{EI} 2$ & 216 & 4 & 4.26 & 4.00 & 4 & 0.666 \\
\hline El3 & 216 & 4 & 4.33 & 4.00 & 5 & 0.715 \\
\hline El4 & 216 & 4 & 4.08 & 4.00 & 4 & 0.755 \\
\hline EI5 & 216 & 4 & 2.60 & 2.00 & 2 & 1.177 \\
\hline EI6 & 217 & 3 & 4.29 & 4.00 & 4 & 0.704 \\
\hline El7 & 217 & 3 & 3.82 & 4.00 & 4 & 0.882 \\
\hline El8 & 211 & 9 & 3.75 & 4.00 & 4 & 0.999 \\
\hline EI9 & 217 & 3 & 4.03 & 4.00 & 4 & 0.775 \\
\hline El10 & 215 & 5 & 4.21 & 4.00 & 4 & 0.830 \\
\hline El11 & 217 & 3 & 3.61 & 4.00 & 4 & 1.079 \\
\hline El12 & 217 & 3 & 3.78 & 4.00 & 4 & 0.880 \\
\hline El13 & 215 & 5 & 3.90 & 4.00 & 4 & 0.867 \\
\hline El14 & 206 & 14 & 4.36 & 4.00 & 4 & 0.622 \\
\hline El15 & 215 & 5 & 3.93 & 4.00 & 4 & 0.805 \\
\hline El16 & 215 & 5 & 4.05 & 4.00 & 4 & 0.725 \\
\hline El17 & 215 & 5 & 4.13 & 4.00 & 4 & 0.762 \\
\hline El18 & 215 & 5 & 3.74 & 4.00 & 4 & 0.851 \\
\hline El19 & 214 & 6 & 4.05 & 4.00 & 4 & 0.714 \\
\hline EI20 & 211 & 9 & 4.10 & 4.00 & 4 & 0.798 \\
\hline EI21 & 211 & 9 & 4.00 & 4.00 & 4 & 0.822 \\
\hline EI22 & 209 & 11 & 4.09 & 4.00 & 4 & 0.691 \\
\hline EI23 & 208 & 12 & 4.25 & 4.00 & 4 & 0.635 \\
\hline EI24 & 211 & 9 & 4.37 & 4.00 & 5 & 0.688 \\
\hline EI25 & 213 & 7 & 3.92 & 4.00 & 4 & 0.672 \\
\hline EI26 & 211 & 9 & 3.91 & 4.00 & 4 & 0.805 \\
\hline El27 & 211 & 9 & 3.78 & 4.00 & 4 & 0.756 \\
\hline El28 & 213 & 7 & 2.16 & 2.00 & 1 & 1.388 \\
\hline EI29 & 212 & 8 & 3.67 & 4.00 & 4 & 0.861 \\
\hline El30 & 211 & 9 & 4.10 & 4.00 & 4 & 0.709 \\
\hline El31 & 212 & 8 & 4.03 & 4.00 & 4 & 0.630 \\
\hline El32 & 212 & 8 & 4.03 & 4.00 & 4 & 0.630 \\
\hline El33 & 212 & 8 & 3.04 & 3.00 & 2 & 1.174 \\
\hline
\end{tabular}

$N$, number; Std., standard.

TABLE 3: Goodness of fit test.

\begin{tabular}{lcccc}
\hline Model & $\mathbf{- 2}$ Log likelihood & Chi-square & $d f$ & Sig. \\
\hline Intercept only & 100.483 & - & - & - \\
Final & 72.378 & 28.105 & 6 & 0.031 \\
\hline
\end{tabular}

Note: Link function, Logit.

$d f$, degrees of freedom; Sig, significance.

relative to a perfect model. In this regard, a good result is to fail to reject the null hypothesis. The study calculated the Pearson and deviance $p$-values to be 0.999 and 0.994 , respectively (see Table 4 ). The $p$-values are both more than the 0.05 threshold and this means that there is no significant statistical information to reject the null hypothesis.

The test of parallel lines is also known as the test for proportional odds assumption. The null hypothesis under the assumption is that the slope coefficients in the model are the same across response categories (and lines of the same slope are parallel). The goal here was to fail to reject the null hypothesis because this would prove the study model to be good.

The $p$-value for the test of parallel lines is 0.94 (see Table 5), which is greater than the threshold 0.05. This means that there is not enough evidence to reject the null hypothesis
TABLE 4: Proportional odds chi-square test.

\begin{tabular}{lccc}
\hline Variable & Chi-square & Df & Sig. \\
\hline Pearson & 24.032 & 48 & 0.999 \\
Deviance & 27.057 & 48 & 0.994 \\
\hline
\end{tabular}

Note: Link function, Logit.

$d f$, degrees of freedom; Sig, significance.

TABLE 5: Test for parallel lines.

\begin{tabular}{lcccc}
\hline Model & $\mathbf{- 2}$ Log likelihood & Chi-square & $d f$ & Sig. \\
\hline Null hypothesis & 72.378 & - & - & - \\
General & 70.610 & 1.768 & 6 & 0.940 \\
\hline
\end{tabular}

Note: The null hypothesis states that the location parameters (slope coefficients) are the same across response categories. Link function, Logit.

$d f$, degrees of freedom; Sig, significance.

and a conclusion can be made that the proportional odds assumption holds for the study model. Lastly, a most important aspect of the proportional odds analysis is the parameter estimates, and in this case, the results are shown in Table 6.

The column 'estimate' gives information on the log odds of the independent variables. One unit increase in age (from a younger age group to the next older group) multiplies the odds of scoring high in EI by $\log (-0.241)$, which is 0.786 given that other variables are held constant. However, the $p$-value of 0.422 shows that the differences in age of respondents do not significantly affect the propensity of scoring high levels of EI.

The working experience of respondents has an estimated beta of 0.153 , which means that a unit increase in the number of years of experience multiplies the odds of scoring high levels of EI by $16.5 \%$ given that the other independent variables are held constant. This means that EI levels were rising by the length of work experience; however, the change is not significant as shown by the $p$-value of 0.59 , which is greater than the significant level 0.05 .

The estimate for gender $=1$ (male participants) is 0.241 , which is above zero and this shows that keeping other independent variables constant, the male participants are $27.2 \%$ more likely to score high level of EI than their female counterparts. This is because the odds ratio is greater than 0 . Despite the difference in the scoring of EI level for male and female participants as exhibited by the odds ratio, the $p$-value on this is 0.566 , thus, greater than the threshold of 0.05 indicating that the differences in the scoring of EI levels are not significant based on the gender.

In terms of ethnicity of the participants, Africans had an estimated ratio of 0.292 , which is greater than zero and this shows that the African participants had a cumulative ratio of $34 \%$ chance of scoring higher scores of EI than were the participants belonging to the 'other' race which was used as the reference group. The white participants had an odds ratio of 1.552 and when exponentiated meant that the magnitude of them scoring high on EI than the 'other' race was 4.723 times. The mixed race group had a beta or odds ratio of -1.816 and this is less than zero. This means that the mixed race group scored low on EI than the reference 'other' ethnicity group. In essence, the mixed race scored lower level of EI by a cumulative odds ratio of 0.163 times that of the 'other' race. 


\begin{tabular}{|c|c|c|c|c|c|c|c|}
\hline \multirow[t]{2}{*}{ Variable } & \multirow[t]{2}{*}{ Estimate } & \multirow[t]{2}{*}{ Std. error } & \multirow[t]{2}{*}{ Wald } & \multirow[t]{2}{*}{$d f$} & \multirow[t]{2}{*}{ Sig. } & \multicolumn{2}{|c|}{$95 \%$ Confidence interval } \\
\hline & & & & & & Lower bound & Upper bound \\
\hline \multicolumn{8}{|l|}{ Threshold } \\
\hline [Emot_Intel = 3] & -3.096 & 3.311 & 0.874 & 1 & 0.350 & -9.586 & 3.394 \\
\hline$[$ Emot_Intel $=4]$ & 2.566 & 3.306 & 0.602 & 1 & 0.438 & -3.914 & 9.045 \\
\hline \multicolumn{8}{|l|}{ Location } \\
\hline AGE & -0.241 & 0.300 & 0.644 & 1 & 0.422 & -0.829 & 0.347 \\
\hline
\end{tabular}

$d f$, degrees of freedom; Sig., significance; Std., standard; Emot_Intel, emotional intelligence.

TABLE 7: $P$-values on chi-square and analysis of variance.

\begin{tabular}{lcccc}
\hline Variable & \multicolumn{4}{c}{$\boldsymbol{P}$-values } \\
\cline { 2 - 5 } & $\begin{array}{c}\text { Gender } \\
\text { (chi-square) }\end{array}$ & $\begin{array}{c}\text { Age } \\
\text { (one-way } \\
\text { ANOVA) }\end{array}$ & $\begin{array}{c}\text { Working } \\
\text { experience } \\
\text { (one-way ANOVA) }\end{array}$ & $\begin{array}{c}\text { Ethnicity } \\
\text { (one-way } \\
\text { ANOVA) }\end{array}$ \\
\hline Expression of emotions & 0.182 & 0.459 & 0.331 & 0.727 \\
Use of emotions & 0.062 & 0.540 & 0.364 & 0.199 \\
Perception of emotions & 0.906 & 0.383 & 0.428 & 0.018 \\
Regulation of emotions & 0.528 & 0.656 & 0.521 & 0.191 \\
\hline
\end{tabular}

ANOVA, analysis of variance.

An exploratory factor analysis was conducted on the SEIS data and four factors had Eigen values greater than 1 . These factors were interpreted as an expression of emotions, use of emotions, and a perception of emotion and regulation of emotion. Chi-square and ANOVA tests were performed in terms of gender and the other three factors, respectively. These tests were carried out in order to substantiate the findings from the proportional odds test. Table 7 shows the obtained $p$-values after running the respective chi-square and ANOVA tests. All the $p$-values, but one, are greater than the significant level of 0.05 , and this is evidence that even though some differences are observed amongst participants based on their gender, age, working experience and ethnic background, the differences are not significant. The only significant differences $(p=0.018)$ are observed for ethnic background on the 'perception of emotion' factor.

\section{Discussion}

\section{Outline of results}

The main objective of the study was to investigate the influence of demographic variables on the level of EI amongst ECAs at a selected institution. In this regard, there were some differences observed for the EI responses based on gender. Even though the differences were found to be insignificant, male participants were reported to be more likely to score low on EI than the female participants. The insignificant differences may be explained by the changing of gender roles and the exposition of similar work and family challenges for both the male and female participants. Even though the study observed some differences in the level of EI scores based on participants' work experience, the differences were not significant. This may be explained by the fact that the participants were all ECAs and do face similar work and career challenges, and therefore, their EI levels may not significantly differ. The study observed an unexpected result as far as participants' age was concerned. The older participants showed more probability to score low on EI than the younger participants. However, the difference observed was statistically deemed insignificant. This finding is opposed by Chen et al. (2015) and Frank et al. (2015), who reported a positive relationship between respondents' age and their level of EI.

In terms of the participants' ethnicity, differences amongst groups were observed. The white participants scored higher on EI than all other groups. The African participants scored higher than the mixed race and the 'other' whilst the mixed race participants scored the least EI scores. It is possible that the mixed race and 'other' respondents scored the least as a result of the fact that they were significantly less represented than the black and white respondents. However, the differences were deemed insignificant as a result of the lack of statistical evidence. The responses on the perception of emotion factor were found to significantly differ with participants' ethnic background. The difference may be explained in line with the effect of globalisation in which the workforce in an organisation is becoming significantly mixed as labour mobility across continents and nation increases (Hossein, 2015; Robertson, 2010). Only a few studies also report significant differences in EI based on the race variable (Dewi et al., 2017; Sergio et al., 2015).

Importantly, in line with the main hypothesis of the study, the demographic variables studied did not collectively significantly influence the level of EI amongst ECAs even though differences were observed.

\section{Practical implications}

The respondents to the study indicated to belong to different groups or categories of varying demographic variables. This observation proves that the academic workforce demographics are increasingly becoming diversified and therefore inquiries into demographic dynamics are important (Ang et al., 2015; Maduramente, 2015). This study focused on the ECAs, their demographical attributes and their EI levels. The results obtained in this study are therefore important for career counselling and personal career development (Casper \& Storz, 2016). The issue of demographics encourages career counsellors to personalise their services based on demographical attributes (Savickas, 2011). The levels of EI amongst the ECAs show that EI is yet an important aspect of individual development, adaptation and performance.

Because some differences between male and female levels of EI were observed, the human resource manager may need 
to continue to make efforts to reduce this difference as far as is possible to avoid sexism in making inferences concerning perspectives (Frank et al., 2015). Significant differences were found amongst ECAs of different ethnic backgrounds with respect to the perception of emotion. In this regard, the cultural gap seems to be still visible in the workplace as well as in the academic profession. This implies that more crosscultural interaction and more team-building activities are still needful in order to continue to foster common ground and reasoning amongst individuals in the same profession (Dewi et al., 2017). Otherwise, racial inferences may continue to sprout, even out of contexts. Thus, organisations nowadays desire to hire individuals who exhibit high adaptability and flexibility needful to be effective in circumstances where diversity is present.

The study also reported some differences in the level of EI based on the years of experience. Though the differences were proven insignificant, EI scores rose with the years of experience. This may imply that ECAs may need to endure their circumstances hoping that with more experience they become an effective manager of their own productivity and development. However, in order to gain experience, security of jobs is important. ECAs are mostly in non-permanent position (Matthews, Lodge, \& Bosanquet, 2014; Sutherland \& Taylor, 2011) and this might be an unfavourable predicament as far as career advancement is concerned.

In terms of the age of respondents, the study reported that the younger respondents scored higher EI scores than their older counterparts. This is contrary to the expectation that as people grow older, they become more experienced and mature to handle some circumstances that the younger generation struggle with (Chen et al., 2015; Sergio et al., 2015). The unexpected finding of this study shows the complexities inherent in a diverse workforce whereby things might not always seem to be as they appear to be. In this light, there is a need for continuous information gathering and assessment of the workforce in order to have more informed decisions on matters that pertain to personnel.

The presence of many factors affecting the personality, decisions and behaviours of individuals implies that change is imminent and therefore interval analysis of gaps and differences may be necessary.

\section{Limitations and recommendations}

This study was conducted under some limitations. External validity was compromised because the sample surveyed was selected through non-probability sampling procedure and also the data were collected from only one selected university. In this light, caution needs to be exercised in generalising findings to all the ECAs in the country or other institutions. Secondly, this study is part of a bigger project in which respondents had to answer questions pertaining to more than one variable on a self-administered instrument. This made the study risk to spurious variance as a result of the measurement instrument and not the constructs.
Despite the fact that the sample size used was sufficient for the purposes of this study, it must be noted that the sample did not sufficiently represent the characteristics of the population of interest. Lastly, EI is exhibited in theory as a personality trait or ability which is influenced by various factors. This study only included four demographic variables, which do not exhaustively represent all the factors that influence EI. Caution should also be taken in generalising the findings of this study. Regardless of the mentioned limitations to this study, the obtained findings may still be relevant to practice for ECAs, career counsellors and institutions of higher learning.

\section{Conclusion}

This study contributes to the literature of EI and ECAs. The findings of the study have implications on ECAs as they seek to personally grow and develop in their career, institutions of higher learning and their human resources functions and career counsellors. Differences in the levels of EI amongst ECAs were observed based on the various demographic variables. Even though the majority of these differences were statistically insignificant, it can be stated that the demographic variables may have a real impact on EI. The study suggests that further research needs be conducted in which comparisons can be made between early career professionals and those already established.

\section{Acknowledgements}

The researchers are indebted to the Govan Mbeki Research and Development Centre at the University of Fort Hare for the financial support and workshops which also became a point of contact with respondents.

\section{Competing interests}

The authors declare that there were no personal circumstances, relationships and financial gain that influenced them in data collection, analysis, interpretation and reporting.

\section{Authors' contributions}

M.M. was the principal researcher whilst W.T.C. was the supervisor (promoter) of the research. The researchers also declare that the views expressed in this study are their own and not the official position of any institution.

\section{References}

Andrés, A. R., Asongu, S. A., \& Amavilah, V. (2015). The impact of formal institutions on knowledge economy. Journal of the Knowledge Economy, 6(4), 1034-1062. $\mathrm{https} / / /$ doi.org/10.1007/s13132-013-0174-3

Ang, S., Rockstuhl, T., \& Tan, M. L. (2015). Cultural intelligence and competencies. International Encyclopedia of the Social \& Behavioral Sciences, 5(2), 433-439. https://doi.org/10.1016/B978-0-08-097086-8.25050-2

Antonakis, J., Ashkanasy, N. M., \& Dasborough, M. T. (2009). Does leadership need emotional intelligence? The Leadership Quarterly, 20(2), 247-261. https://doi. org/10.1016/j.leaqua.2009.01.006

Antonakis, J., \& Dietz, J. (2011). More on testing for validity instead of looking for it. Personality and Individual Differences, 50(3), 418-421. https://doi.org/10.1016/j. paid.2010.10.008

Armour, B. (2012). Emotional intelligence and learning \& teaching in higher education: Implications for bioscience education. Investigations in University Teaching and Learning, 8, 4-10. 
Bailey, S. (2015). Emotional intelligence predicts job performance. The 7 Traits That Help Managers Relate. Retrieved from https://www.forbes.com/sites/sebastianbailey/ 2015/03/05/emotional-intelligence-predicts-job-performance-the-7-traits-thathelp-managers-relate/\#64251e2c4124

Bande, B., Fernández-Ferrín, P., Varela, J. A., \& Jaramillo, F. (2015). Emotions and salesperson propensity to leave: The effects of emotional intelligence and resilience. Industrial Marketing Management, 44, 142-153. https://doi.org/ 10.1016/j.indmarman.2014.10.011

Bar-On, R. (2010). Emotional intelligence: An integral part of positive psychology. South African Journal of Psychology, 40(1), 54-62. https://doi.org/10.1177/ 008124631004000106

Beldoch, M. (1964). Sensitivity to expression of emotional meaning in three modes of communication. In J. R. Davitz (Ed.), The communication of emotional meaning (pp. 31-42). New York: McGraw-Hill.

Bissessar, C. (2011). Gender, age differences and emotional intelligences: Implications for workforce development, The University of the West Indies, Jamaica.

Black, M. (2015). Advancing emotional intelligence (EI) in higher education curriculum The advantage for students, their future careers and employers. Posters, 8 .

Retrieved from https://epublications.bond.edu.au/learn_teach_posters2015/8

Botma, N. (2009). Emotion experience, emotional intelligence and well-4
Africa (Doctoral dissertation). North-West University Depository.

Bozionelos, N., \& Singh, S. K. (2017). The relationship of emotional intelligence with task and contextual performance: More than it meets the linear eye. Personality and Individual Differences, 116, 206-211. https://doi.org/10.1016/j.paid.2017. 04.059

Brock, T. (2010). Young adults and higher education: Barriers and breakthroughs to success. Future of Children, 20(1), 109-132. https://doi.org/10.1353/foc.0.0040

Casper, S., \& Storz, C. (2016). Bounded careers in creative industries: Surprising patterns in video games. Industry and Innovation, 24(3), 213-248. https://doi. patterns in video games. Industry and
org/10.1080/13662716.2016.1224705

Chen, Y., Peng, Y., \& Kirk, R. (2015). Age differences in emotional intelligence: Crosscultural evidence from American and Chinese adults. The Gerontologist, 55(2), 79-91.

Chengting, J., Jijun, L., Yuan, L., Wei, F., \& Xuqun, Y. (2015). The mediating role of workplace social support on the relationship between trait emotional intelligence and teacher burnout. Teaching and Teacher Education, 51, 58-67. https://doi. org/10.1016/j.tate.2015.06.001

Coates, H., Goedegebuure, L., \& Meek, V. L. (2015). Increasing the attractiveness of the academic profession: A challenge for management. In $U$. Teichler \& W. Cummings (Eds.), Forming, recruiting and managing the academic profession. The changing academy - The changing academic profession in international comparative perspective (Vol. 14, pp. 297-315). Cham: Springer.

Collins, C., \& Cooper, J. (2014). Emotional intelligence and the qualitative researcher. International Journal of Qualitative Methods, 13, 88-103. https://doi.org/10.1177/ 160940691401300134

Dewi, Z. L., Halim, M. S., \& Derksen, J. (2018). Emotional intelligence competencies of three different ethnic groups in Indonesia. Asian Ethnicity, 19(1), 36-58. https:// doi.org/10.1080/14631369.2017.1310615

Dippenaar, M., \& Schaap, P. (2017). The impact of coaching on the emotional and social intelligence competencies of leaders. South African Journal of Economic and Management Sciences, 20(1), 1-16. https://doi.org/10.4102/sajems.v20i1.1460

Ebrahimi, M. R., Khoshsima, H., \& Zare Behtash, E. (2018). The impacts of emotional intelligence enhancement on Iranian intermediate EFL learners writing skill. International Journal of Instruction, 11(1), 437-452. https://doi.org/10.12973/iji. 2018.11130a

Fiori, M., \& Antonakis, J. (2011). The ability model of emotional intelligence: Searching for valid measures. Personality and Individual Differences, 50(3), 329-334. https://doi.org/10.1016/j.paid.2010.10.010

Frank, C. K., Baron-Cohen, S., \& Ganzel, B. L. (2015). Sex differences in the neural basis of false-belief and pragmatic language comprehension. Neurolmage, 105, 300-311. https://doi.org/10.1016/j.neuroimage.2014.09.041

Gardner, H. (1983). Frames of mind: The theory of multiple intelligences. New York: Basic Books.

Goleman, D. (1995). Emotional intelligence: Why it can matter more than IQ. New York: Bantam Books.

Gunkel, M., Schlägel, C., \& Engle, R. L. (2013). Culture's influence on emotional intelligence: An empirical study of nine countries. Journal of Internationa Management, 20(2), 256-274. https://doi.org/10.1016/j.intman.2013.10.002

Hemalatha, S. (2016). An empirical study on impact of demographic factors on emotional intelligence. International Journal of Commerce and Business Management, 7(2), 413-416. https://doi.org/10.15740/HAS/IJCBM/7.2/413-416

Hossein, R. N. (2015). The effect of nationality differences on the emotional intelligence of leaders (Doctoral thesis). Walden Dissertations and Doctoral Studies.

James, P., \& Steger, M. B. (2014). A genealogy of globalization: The career of a concept. Globalizations, 11(4), 417-434. https://doi.org/10.1080/14747731.2014.951186

Jonker, C. S., \& Vosloo, C. (2008). The psychometric properties of the Schutte Emotional Intelligence Scale. South African Journal for Industrial Psychology, 34 21-30. https://doi.org/10.4102/sajip.v34i2.689

Jorfi, H., Yaccob, H. F. B., \& Shah, I. M. (2011). The relationship between demographic variables, emotional intelligence, communication effectiveness, motivation, and job satisfaction. International Journal of Academic Research in Business and Socia Sciences, 1(1), 35-58. https://doi.org/10.6007/ijarbss.v1i1.7

Kaufmann, L., \& Wagner, C. M. (2017). Affective diversity and emotional intelligence in cross-functional sourcing teams. Journal of Purchasing and Supply Management, 23(1), 5-16. https://doi.org/10.1016/j.pursup.2016.07.004
Kónya, V., Matić, D., \& Pavlović, J. (2016). The influence of demographics, job characteristics and characteristics of organizations on employee commitment. Acta Polytechnica Hungarica, 13(3), 119-138.

Kumar, J. A., \& Muniandy, B. (2012). The influence of demographic profiles on emotional intelligence: A study on polytechnic lecturers in Malaysia. Internationa Online Journal of Educational Sciences, 4(1), 62-70.

Maduramente, A. M. G. (2015). The effect of emotional intelligence, ethnic identity, and ethnicity on college adjustment (UB Theses and Dissertations in the Proquest database). Univeristy of Buffalo, New York.

Matthews, K. E., Lodge, J. M., \& Bosanquet, A. (2014). Early career academic perceptions, attitudes and professional development activities: Questioning the teaching and research gap to further academic development. International Journal for Academ Development, 19(2), 112-124. https://doi.org/10.1080/1360144X.2012.724421

Mayer, C.-H., Oosthuizen, R. M., \& Surtee, S. (2017). Emotional intelligence in South African women leaders in higher education. South African Journal of Industrial
Psychology/SA Tydskrif vir Bedryfsielkunde, 43(1), 1-12. https://doi.org/10.1177/ Psychology/SA Tydsk
1754073916639667

Mayer, J. D., Caruso, D. R., \& Salovey, P. (2016). The ability model of emotional intelligence: Principles and updates. Emotion Review, 8(4), 290-300.

Moon, T. W., \& Hur, W. (2011). Emotional intelligence, emotional exhaustion, and job performance. Social Behavior and Personality: An International Journal, 39(8), 1087-1096. https://doi.org/10.2224/sbp.2011.39.8.1087

Murphy, K. R. (2014). A critique of emotional intelligence: What are the problems and how can they be fixed? New York: Psychology Press.

Oatley, K., \& Johnson-Laird, P. N. (2014). Cognitive approaches to emotion. Trends in Cognitive Sciences, 18, 134-140. https://doi.org/10.1016/j.tics.2013.12.004

Petrides, K. V. (2011). Ability and trait emotional intelligence. In T. Chamorro-Premuzic, A. Furnham, \& S. von Stumm (Eds.), The Blackwell-Wiley handbook of individual differences (pp. 656-678). New York: Wiley.

Petrides, K. V., Pita, R., \& Kokkinaki, F. (2007). The location of trait emotional intelligence in personality factor space. British Journal of Psychology, 98, 273-289. https://doi.org/10.1348/000712606X120618

Pooja, P., \& Kumar, P. (2016). Demographic variables and its effect on emotional intelligence: A study on Indian service sector employees. Annals of Neurosciences, 23(1), 18-24. https://doi.org/10.1159/000443552

Pradhan, R. K., Jena, L. K., \& Singh, S. K. (2017). Examining the role of emotional intelligence between organizational learning and adaptive performance in Indian manufacturing industries. Journal of Workplace Learning, 29(3), 235-247. https:// manufacturing industries. Journal of
doi.org/10.1108/JWL-05-2016-0046

Ramesar, S., Koortzen, P., \& Oosthuizen, R. M. (2009). The relationship between emotional intelligence and stress management. South African Journal of Industria Psychology, 35(1), 39-48. https://doi.org/10.4102/sajip.v35i1.443

Robertson, E. (2010). What is the relationship between emotional intelligence and administrative advancement in an urban school division? Virginia: VCU Scholars Compass.

Salovey, P., \& Mayer, J. D. (1990). Emotional intelligence. Imagination, Cognition and Personality, 9(3), 185-211. https://doi.org/10.2190/DUGG-P24E-52WK-6CDG

Savickas, M. (2011). Career counseling. Washington, DC: American Psychological Association.

Schutte, N. S., Malouff, J. M., Hall, L. E., Haggerty, D. J., Cooper, J. T., Golden, C. J., \& Dornheim, L. (1998). Development and validation of a measure of emotiona intelligence. Personality and Individual Differences, 25, 167-177. https://doi. org/10.1016/S0191-8869(98)00001-4

Sergio, R. P., Dungca, A. L., \& Ormita, L. A. G. (2015). The demographic variables and emotional intelligence as correlates of work values: A cross-cultural examination towards organisational change. Journal of Economics, Business and Management, 3(2), 167-175. https://doi.org/10.7763/JOEBM.2015.V3.175

Serrat, O. (2017). Understanding and developing emotional intelligence (pp. 329-339). Singapore: Knowledge Solutions, Springer.

Shukla, A., \& Srivastava, R. (2016). Examining the effect of emotional intelligence on socio-demographic variable and job stress among retail employees. Cogent Business \& Management, 3(1), 1201905-1201923. https://doi.org/10.1080/2331 Business \& Manage
1975.2016.1201905

Smith, L., Ciarrochi, J., \& Heaven, P. C. L. (2008). The stability and change of trait emotional intelligence, conflict communication patterns, and relationship satisfaction: A one-year longitudinal study. Personality and Individual Differences, 45, 738-743. https://doi.org/10.1016/j.paid.2008.07.023

Steyn, T. S. (2010). The role of gender in the relationship between emotional intelligence and psychological well-being. Master's Dissertation Clinical Psychology, North-West Universit: Potchefstroom.

Sutherland, K., \& Taylor, L. (2011). The development of identity, agency and community in the early stages of the academic career. International Journal for Academic
Development, 16(3), 183-186. https://doi.org/10.1080/1360144X.2011.596698

Thomas, C., Cassady, J., \& Heller, M. (2017). The influence of emotional intelligence, cognitive test anxiety, and coping strategies on undergraduate academic
performance. Learning and Individual Differences, 55, 40-48. https://doi.org/ performance. Learning and
$10.1016 /$ j.lindif.2017.03.001

Vandervoort, D. J. (2006). The importance of emotional intelligence in higher education Current Psychology, 25(1), 4-7. https://doi.org/10.1007/s12144-006-1011-7

Vratskikh, I., Masa'deh, R., Al-Lozi, M., \& Maqableh, M. (2016). The impact of emotional intelligence on job performance via the mediating role of job satisfaction International Journal of Business and Management, 11(2), 69-91. https://doi. org/10.5539/ijbm.v11n2p69

Zysberg, L., Orenshtein, C., Gimmon, E., \& Robinson, R. (2017). The role of affect and emotion to cope with stressful situations. International Journal of Stress Management, 24(1), 122-136. https://doi.org/10.1037/str0000028 